\title{
Gerenciamento de resíduos no contexto escolar: uma potencial ferramenta para a bioconsciência de alunos do IFMA, Barra do Corda-Maranhão
}

A ambivalência entre o preservar e conservar levou a população a atual diversidade de ideias e às desordens globais, de um lado os grupos ambientais radicais e do outro os compreensivos, sustentáveis e economicamente pujantes, cabendo agora o desafio de desvincular a humanidade desse embate guiando-a para um movimento ambiental libertador onde, mediante a educação ambiental, se construa consciência ambiental e as ações em prol da proteção planetária não necessitem de porquês para ganharem sentido e relevância. A participação é um elemento fundamental em todo processo social, em especial nos arranjos econômicos e ambientais uma vez que demandam, acima de tudo, a identificação e afinidade ideológica de seus partícipes. No bojo das ações de educação ambiental, fomentar meios para que a sociedade se identifique com os projetos e sinta afinidade com as correntes ambientais deve ser o primeiro passo para a concepção de uma comunidade engajada. Nesse sentido o presente projeto buscou articular ações no espaço físico do IFMA/Campus Barra do Corda com concepções teóricas passo para a concepção de uma comunidade engajada. Nesse sentido o presente projeto buscou articular ações no espaço físico do IFMA/Campus Barra do Corda com concepções teóricas
metodológicas do grupo Boticário, unindo iniciativa privada com iniciativa pública, no sentido de obter uma justaposição de olhares acerca do reuso e reciclagem de resíduos sólidos provenientes de produtos de perfumaria, cosméticos e de resíduos orgânicos, favorecendo a cadeia produtiva de uma organização solidária, a Associação de Catadores de Materiais Recicláveis (ASCAMAR) em São Luís - MA. O projeto foi executado com uma metodologia descritiva, exploratória e quantitativa, coletando aproximadamente 33,696 Kg de resíduos, dentre ele embalagens de papel, plástico, metal, vidro, além de borra de café, todos direcionado para práticas de reciclagem, seja por meio da ASCAMAR ou distribuídos para uso como complemento de adubação (borra de café desidratada). Dessa forma, o projeto contribuiu para debates sobre o tema, fortalecimento da eco consciência dos participantes (em especial dos alunos), para a promoção do engajamento da comunidade escolar em dinâmicas de educação ambiental, concluindo-se que devido sua importância geral o referido projeto deve ser retomado tão logo as condições sanitárias permitam, a fim de abranger mais alunos para assim ocorrer inclusão de novas turmas, novos parceiros e novas comunidades a serem atendidas.

Palavras-chave: Logística reversa; Bioconsciência; Resíduos.

\section{Waste management in the school context: a potential tool for the bioconsciousness of IFMA students, Barra do Corda-Maranhão}

\begin{abstract}
The ambivalence between preserving and conserving led the population to the current diversity of ideas and to global disorders, on the one hand the radical environmental groups and on the other the comprehensive, sustainable and economically powerful ones, now facing the challenge of detaching humanity from this clash guiding it towards a liberating environmental movement where, through environmental education, environmental awareness is built and actions in favor of planetary protection do not need whys to gain meaning and relevance. movement where, through environmental education, environmental awareness is built and actions in favor of planetary protection do not need whys to gain meaning and relevance,
Participation is a fundamental element in every social process, especially in economic and environmental arrangements, as it demands, above all, the identification and ideological affinity of its participants. In the midst of environmental education actions, fostering ways for society to identify with projects and feel an affinity with environmental trends should be the first step in the design of an engaged community. In this sense, the present project sought to articulate actions in the physical space of the IFMA/Campus Barra do Corda with theoretical methodological concepts of the Boticário group, joining private initiative with public initiative, in order to obtain an overlapping of views about the reuse and recycling of solid waste from perfumery, cosmetics and organic waste products, favoring the production chain of a solidarity organization, the Association of Waste Pickers (ASCAMAR) in São Luís - MA. The project was carried out with a descriptive, exploratory and quantitative methodology, collecting approximately $33.696 \mathrm{~kg}$ of waste, including paper, plastic, metal, glass packaging, in addition to coffee grounds, al directed to recycling practices, either through ASCAMAR or distributed for use as a fertilizer supplement (dehydrated coffee grounds). Thus, the project contributed to debates on the theme, stren the strengthening the participants' eco-conscience (especially students), to promote the engagement of the school community in environmental education dynamics, concluding that due to its
general importance, the referred project it must be resumed as soon as the sanitary conditions permit, in order to reach more students so that new classes, new partners and new communities to be served will be included.
\end{abstract}

Keywords: Reverse logistics; Bioconsciousness; Waste.

Topic: Desenvolvimento, Sustentabilidade e Meio Ambiente

Reviewed anonymously in the process of blind peer.

Nilson dos Santos Loiola (iD

Instituto Federal do Maranhão, Brasil

http://lattes.cnpq.br/4277571699501201

http://orcid.org/0000-0002-4641-5864

nilson.loiola@ifma.edu.br

Alane Oliveira Nascimento

Instituto Federal do Maranhão, Brasil

http://lattes.cnpq.br/2854837161810882

http://orcid.org/0000-0003-2873-7365

alane.nascimento@ifma.edu.br

Kelma Morais Silva (iD

Instituto Federal do Maranhão, Brasil

http://lattes.cnpq.br/9104380829064796

http://orcid.org/0000-0002-8057-6178

kelma.silva@acad.ifma.edu.br

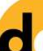

DOI: 10.6008/CBPC2179-6858.2020.007.0045
Received: 04/12/2020

Approved: 21/12/2020
Referencing this:

LOIOLA, N. S.; ASCIMENTO, A. O.; SILVA, K. M.. Gerenciamento de resíduos no contexto escolar: uma potencial ferramenta para a bioconsciência de alunos do IFMA, Barra do Corda-Maranhão. Revista Ibero Americana de Ciências Ambientais, v.11, n.7, p.577-586, 2020. DOI: http://doi.org/10.6008/CBPC2179-6858.2020.007.0045 


\section{INTRODUÇÃO}

Nos primórdios dos debates ambientais a ambivalência entre o preservar e conservar levou a população a atual diversidade de ideias e às desordens globais, de um lado os grupos ambientais radicais e do outro os compreensivos, sustentáveis e economicamente pujantes, cabendo agora o desafio de desvincular a humanidade desse embate guiando-a para um movimento ambiental libertador onde, mediante a educação ambiental, se construa consciência ambiental e as ações em prol da proteção planetária não necessitem de porquês para ganharem sentido e relevância, se materializando em práticas ecosóficas não pautadas em obrigações, punições ou sanções, mas numa realização ambiental coletiva, espontânea e participativa.

A participação é um elemento fundamental em todo processo social, em especial nos arranjos econômicos e ambientais uma vez que demandam, acima de tudo, a identificação e afinidade ideológica de seus partícipes. No bojo das ações de educação ambiental, fomentar meios para que a sociedade se identifique com os projetos e sinta afinidade com as correntes ambientais deve ser o primeiro passo para a concepção de uma comunidade engajada.

Uma forma de transformar a sociedade organizada, globalizada e economicamente ativa também participativa nos aspectos ambientais é a sua organização de acordo os preceitos da economia solidária. Como afirma Gomes et al. (2007) a prática solidária e colaborativa focada no ser humano como o sujeito e fim nas atividades econômicas, baseada nos aspectos culturais do mesmo, sem enfoques na mera acumulação de riquezas e capital, é o que define a economia solidária.

Atualmente, com base no Princípio dos 3 R's (Reduzir, Reutilizar e Reciclar), há três possíveis maneiras de combater ou minimizar a geração de resíduos: 1) Mudar os padrões de consumo para reduzir/evitar a geração de resíduos; 2) Reutilizar produtos/embalagens para outros fins; 3) Reciclar ou tratar os resíduos de alguma forma para que eles tenham um ciclo de vida mais longo. Essas três medidas são bem conhecidas e, seguindo os preceitos da Política Nacional de Resíduos Sólidos, devem ser adotadas pela ordem da redução, seguida da reutilização e, caso não possa mais valer-se das opções anteriores, deve-se implementar a reciclagem, na pior da hipótese os resíduos deverão passar por processos de tratamento e pela busca de uma disposição adequada, como demonstra a figura 1 sobre as prioridades para a gestão dos resíduos (STURZENEGGER, 2014; BRASIL, 2010).

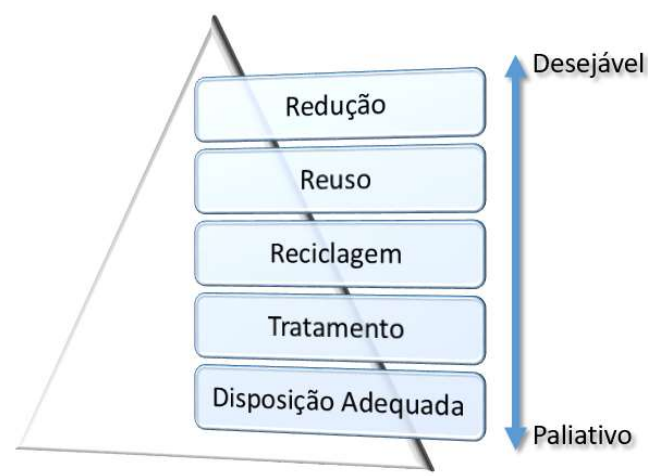

Figura 1: Prioridades na gestão de resíduos. 
Parte da problemática se concentra na dualidade de ideias entre os economistas/tecnólogos e os demógrafos/geólogos que, em seus infinitos diálogos, discorrem sobre a esgotabilidade dos recursos naturais, polarizando a opinião pública, levando à escassez dos conceitos a respeito dos $3 R^{\prime}$ s, pelo seu uso em demasia, levando ao descrédito da opinião pública (LOUREIRO et al., 2011).

A opinião pública é um dos pontos fundamentais para todo o progresso ambiental, ela reflete a existência de uma consciência ambiental e está precisa ser entendida como um processo de apropriação e construção ao longo de vivências onde, nessa etapa, as dualidades da retórica mais confundem e cansam do que constroem vivências, perdendo significados por falta de concretude nas ações.

Ao longo dos anos, em meio aos debates e tentativas de práticas, um dos pontos focais das ações tem sido a propagação da reciclagem como uma medida adequada à vida em sociedade. Essa não deve ser encarada como a prioridade, pois a mesma se difundiu na lógica da produção como consumo com o sinônimo de um 'bem-estar'.

A média brasileira de geração de resíduos sólidos domiciliares (RSD), sem contar demais atividades geradoras de resíduos, tem ultrapassado as médias esperadas per capta por produção diária de resíduos. Segundo Sturzenegger (2014), o brasileiro produz uma média de 0,67 Kg/hab/dia de RSD, um valor alto, ainda mais quando se projeta tais números ao longo da média de expectativa de vida da população.

Para tentar reduzir os impactos deixados pelo aumento da geração de resíduos as empresas podem projetar, dentro do seu fluxo logístico de produção/distribuição/comércio/entrega a Logística Reversa, com vistas a resgatar bens para o seu ciclo produtivo ou realizar um descarte adequado, atendendo a legislação ambiental com relação as responsabilidades da empresa para com o meio ambiente, além de fomentar a consciência ecológica dos consumidores por torná-los agentes fundamentais nesse processo de devolução de resíduos (LEITE et al., 2003).

Para a logística reversa funcionar em sua plenitude se faz necessário o investimento em estrutura física adequada para os canais reversos de recolhimento de resíduos e a difusão de informações aos consumidores sobre o descarte adequado e os riscos inerentes ao meio ambiente pela falta de atenção para com o descarte dos resíduos gerados no cotidiano da sociedade. A participação do consumidor é, por tanto, o elemento de destaque na logística reversa e a contribuição da educação ambiental nesse ponto é de fundamental importância por fornecer meios para que o consumidor desenvolva a sua consciência ambiental, viabilizando o retorno de bens pós-consumo (BEZERRA, 2009).

De fato, Reduzir, Reutilizar e Reciclar são as melhores medidas para a gestão consciente dos resíduos e nessa tríade a logística reversa tem destaque por permitir, dependendo do conhecimento agregado e do meio tecnológico empregado, a aplicação desses 3 R's. Na prática o conjunto dos 3 R's ainda é pouco expressivo, com destaques práticos crescentes para a adoção da reciclagem que, quando feita de maneira adequada, também pode resultar em geração de emprego e renda, além de formar novos nichos de estudos ambientais, deixando de ser apenas mais uma ferramenta de fins lucrativos para a indústria.

Esse projeto com finalidade extensionista, submetido a plataforma de projetos do IFMA/ Campus Barra do Corda e contemplado pelo Edital de Extensão sob o número 02/2019, objetivou recolher, classificar, 
quantificar e destinar resíduos sólidos de perfumaria e cosméticos (papel, plástico, metal e vidro), para cooperativas cadastradas junto ao grupo Boticário, sediadas em São Luís - MA, com fins artesanais ou para o comércio de recicláveis. Além disso foi trabalhado o reuso de borra de café como um exemplo de resíduo orgânico gerado pelo cotidiano doméstico, difundindo no conjunto do projeto a metodologia dos 3R's com enfoque a colaboração com o arranjo produtivo da Associação de Catadores de Material Reciclável (ASCAMAR) / São Luís - MA.

A Educação Ambiental busca de forma contínua articular a teoria à prática através de estudos, experiências e projetos que provoquem espaços para reflexões abrangentes, inovadoras e de intervenção junto à sociedade.

Uma das habilidades da educação ambiental é fomentar a aplicabilidade da metodologia dos 3R's adequando-a a diferentes situações que dialoguem com as múltiplas realidades brasileiras. Nesse sentido o presente projeto buscou articular ações no espaço físico do IFMA/ Campus Barra do Corda com concepções teóricas metodológicas do grupo Boticário, unindo iniciativa privada com iniciativa pública, no sentido de obter uma justaposição de olhares acerca do reuso e reciclagem de resíduos sólidos provenientes de produtos de perfumaria, cosméticos e de resíduos orgânicos.

Nessa vertente, o projeto proposto foi de grande relevância no que se referiu às possíveis ações concretas do IFMA/Campus Barra do Corda para a adoção de uma dinâmica de gerenciamento dos resíduos sólidos, enfatizando os impactos da pegada ecológica dos alunos, fomentando princípios ecológicos importantes para a construção de uma eco consciência e demonstrando para a comunidade que a destinação adequada de nossos resíduos podem, não só ajudar o meio ambiente, mas também contribuir para a geração de emprego e renda.

\section{METODOLOGIA}

\section{Caracterização do estudo}

A pesquisa se caracterizou por ser descritiva e exploratória, de análise quantitativa, com coleta e interpretação de dados numéricos obtidos por procedimentos técnicos laboratoriais, sob a ótica de princípios estatísticos, e com base numa pesquisa de referencial teórico realizada em bases de dados indexadas.

Buscou-se explorar a familiaridade sobre a logística reversa como tema central da proposta, levando em consideração a revisão de literatura como a principal ferramenta, além de uma descrição dos resultados por classes de resíduos, instigando possíveis melhorias para o gerenciamento dos resíduos em questão.

Também foi considerado um estudo quantitativo por analisar informações coletadas mediante uma concepção essencialmente matemática, contando valores acumulados ao longo do trabalho e comparando a frequência de cada classe de dados com o todo do qual os mesmos faziam parte, para então representalos através de tabelas e gráficos (CHEMIN, 2015). 


\section{Área de estudo e universo investigado}

O estudo foi realizado junto à comunidade escolar do Instituto Federal de Educação, Ciência e Tecnologia (IFMA)/Campus Barra do Corda - MA, localizado na BR 226, Km 303, Vila Nenzim, sem número no município de Barra do Corda - MA.

Se caracterizou como um projeto de extensão onde, mediante parceria técnica entre a unidade da loja O Boticário da cidade de Barra do Corda - MA e o IFMA/ Campus Barra do Corda, se estendeu as ações de Logística Reversa da loja para o espaço interno da rotina escolar do campus, mantendo o compromisso de ajudar a associação ASCAMAR, já atendida pelo O Boticário, além da comunidade escolar.

As coletas foram realizadas entre os meses de abril a dezembro de 2019 recolhendo embalagens diversas de produtos da classe dos cosméticos e de perfumaria, de qualquer marca, através dos alunos, familiares amigos e comunidade entorno. Além das embalagens foram coletadas borras de café geradas pela copa e cozinha do IFMA/Campus Barra do Corda.

\section{Coleta e classificação do material}

Para a coleta da borra de café foram disponibilizados coletores individualizados e identificados para tal finalidade, recolhidos de dois em dois dias, dispostos na cozinha do refeitório e na copa do setor administrativo. Já para a coleta dos resíduos sólidos provenientes de produtos cosméticos e de perfumaria foi disponibilizado um coletor identificado para tal fim, no formato de urna, fornecido pela unidade da loja $\mathrm{O}$ Boticário de Barra do Corda - MA, empresa com a qual foi mantido parceria para a coleta e destinação adequada dos resíduos sólidos. O material coletado foi separado em: Orgânico (borra de café) e Sólido (papel, plástico, vidro e metal).

\section{Procedimento}

\section{Borra de café}

A borra de café coletada foi disposta em bandejas metálicas, submetida a aquecimento em forno industrial a temperatura de $150^{\circ} \mathrm{C}$, com tempo variável (foi mantido até obter a desidratação, dessa forma o tempo variou de acordo com a quantidade distribuída nas bandejas).

Após desidratada a borra foi acondicionada em pacotes feitos em papel kraft, pesados para registro dos totais recolhidos e os pacotes foram distribuídos para a comunidade como uma possibilidade de composto para adubo.

Obs.: O uso do saco de papel kraft foi importante por se tratar de um produto possível de também fazer parte dos processos rápidos de decomposição bacteriana, agregando material ao adubo e não se transformar num outro resíduo sólido liberado na natureza (a possibilidade de rasgar o papel e misturar com a borra de café ao adubo foi uma instrução repassada à comunidade no ato da distribuição dos pacotes). 


\section{Resíduos sólidos}

A coleta dos resíduos sólidos se deu mensalmente e a cada período esses resíduos foram separados de acordo sua matéria prima principal (papel, plástico, vidro e metal) e cada grupo de resíduos foi pesado para só então ser transportado para a loja O Boticário da cidade (parceira da ação).

\section{Destinação}

Por intermédio do sistema logístico da loja O Boticário os resíduos sólidos foram destinados a uma cooperativa especializada em dar novos destinos a resíduos sólidos, a Associação de Catadores de Materiais Recicláveis (ASCAMAR), com sede em São Luís, capital do Maranhão e a borra de café foi distribuída entre a comunidade escolar como uma proposta de complemento para a adubação de plantas da vivência doméstica.

\section{Tabulação dos dados}

Os dados foram tabulados com o auxílio de planilhas do Excel, seguidas da plotagem de gráficos e montagem de relatórios apresentados para o IFMA/ Campus Barra do Corda, bem como para a montagem de banners de apresentação das ações do projeto, como ocorrido na Semana Nacional de Ciência e Tecnologia de 2019 da referida cidade, cujo o tema geral (Bioeconomia: Diversidade e Riqueza para o Desenvolvimento Sustentável) muito se relacionou com a execução desse projeto.

\section{RESULTADOS}

O projeto teve como principais resultados o engajamento da comunidade do IFMA/ Campus Barra do Corda, o despertar para questionamentos acerca da temática dos 3R's (Reduzir, Reutilizar e Reciclar), propagar que organizar um destino mais adequado não substitui o princípio da redução da geração de resíduos, que deveria ser uma prática inerente aos hábitos de consumo e ainda o apoio gerado a essa corrente da gestão de resíduos sólidos já trabalhada pelo grupo Boticário.

Com relação ao material recolhido e trabalhado no projeto os totais obtidos estão organizados na tabela 1. Ao todo foram recolhidos $33.696,027 \mathrm{~g}$, ou seja, $\cong 33,696 \mathrm{Kg}$ de resíduos que deixaram de circular dentre o lixo comum.

Tabela 1: Resultados alcançados na coleta de resíduos.

\begin{tabular}{l|l|l}
\hline Material recolhido (em gramas) & \multicolumn{2}{l}{} \\
\hline Orgânico & Borra de Café & $9.108,917 \mathrm{~g}$ \\
\hline \multirow{4}{*}{ Sólido } & Papel & $253,562 \mathrm{~g}$ \\
\cline { 2 - 3 } & Plástico & $1.928,486 \mathrm{~g}$ \\
\cline { 2 - 3 } & Metal & $1.477,503 \mathrm{~g}$ \\
\cline { 2 - 3 } & Vidro & $20.927,559 \mathrm{~g}$ \\
\hline
\end{tabular}

Dentre os tipos de resíduos coletados o que teve um valor mais expressivo (em termos de peso quando comparado ao percentual total de material recolhido) foi o recolhimento de embalagens de vidro, enquanto que o papel foi o menos coletado. O percentual de peso em relação a cada tipo de material, pode ser observado na Figura 2 como segue abaixo. 


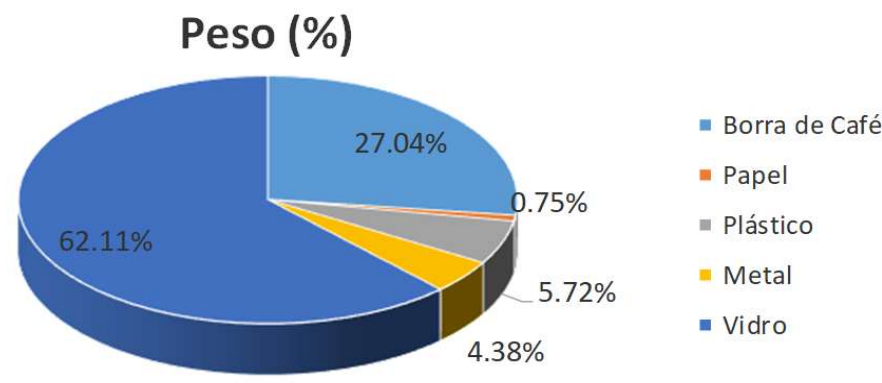

Figura 2: Percentual de cada classe de material coletado com relação ao peso total. Legenda: Porcentagem com relação ao total de 33.696,027 g de material coletado

\section{DISCUSSÃO}

A organização coletiva do trabalho caminhou para os atuais conceitos entorno da chamada economia solidária, deflagrada como resposta aos impactos sociais, políticos e econômicos frente a ascensão e consolidação do consumismo e capitalismo, buscando democracia, respeito a aspectos humanitários e solidariedade (COELHO et al., 2011). Seguindo a definição dos autores, ressalta-se que o presente trabalho apoiou uma organização coletiva de força de trabalho com uma forma ecológica de geração de emprego e renda, unindo a preocupação ambiental com a economia solidária.

A Associação de Catadores de Materiais Recicláveis (ASCAMAR), sediada na cidade de São Luís - MA e contemplada pelo projeto que originou esse artigo, é entendida como um empreendimento democrático, participativo, cooperativo, de organização coletiva do trabalho sendo, por tanto, um empreendimento solidário, com foco na reciclagem e em ações de artesanato.

Para Gaiger (2003) as iniciativas que se baseiam no discurso e na prática da economia solidária são empreendimentos com características ideais de autogestão, democracia, participação, igualitarismo, cooperação, desenvolvimento humano, responsabilidade social, dentre outras características.

Nani (2012) afirma que a reciclagem é uma ação muito importante haja visto que diminui a quantidade de material enterrado ou jogado a céu aberto, evitando a poluição do ar, terra e água, além de prolongar a vida útil dos aterros e gerar emprego pela comercialização.

O trabalho desenvolvido pelo grupo Boticário em parceria com a ASCAMAR, aqui fomentado num ambiente escolar, faz referência a construção de um fluxo reverso da cadeia produtiva do ramo de cosméticos e perfumaria e, assim como afirmam Demajorovic et al. (2014) no estudo sobre o case do Projeto Vira-Lata, a Logística Reversa é fundamental para fechar o ciclo produtivo e otimizar o aproveitamento dos recursos, diminuindo a disposição inadequada de resíduos pelo ambiente.

Demajorovic et al. (2014) também relataram em seu estudo que o fluxo reverso de resíduos sólidos tem influência direta do comércio onde constatou-se uma diminuição expressiva do volume coletado de material de vidro em decorrência desse ser de difícil comercialização, material de difícil processamento e com um baixo valor agregado. Algo parecido foi encontrado nesse trabalho com relação ao quantitativo de papel coletado (Tabela 1), um dado pouco expressivo frente aos demais materiais coletados, o que pode estar relacionado a desvalorização da reciclagem de papel no mercado nacional e a banalização desse tipo de resíduo mal aproveitado. 
Segundo Ricchini (2015) o valor agregado na reciclagem do papel é muito variável, sendo dependente da gramatura do papel, aditivos usados na sua fabricação, dentre outros critérios, e que, para haver uma real valorização desse tipo de reciclagem se faz necessário uma coleta seletiva dentre os variados tipos de papéis, do contrário, um montante desse resíduo coletado sem nenhum critério é sempre comprado baseado no valor do papel mais barato do montante (coincidentemente o que possui mais aditivos e que por isso é o mais difícil para ser reciclado), ou seja, o discurso da reciclagem é na verdade mediado pela importância dessa frente aos ritmos do mercado. Essa postura mercadológica pode estar levando a sociedade à banalização dos resíduos de papel pelo desinteresse em sua coleta e aproveitamento, como foi percebido nesse trabalho (Tabela 1).

De acordo com o Anuário da Reciclagem produzido pela ANCAT (2018), o preço médio dos resíduos de papel coletados e comercializados em 2018 variou de 0,23 a 0,46 R\$/ Kg dependendo do tipo de papel, o que é pouco expressivo frente a valorização das demais classes de resíduos comercializados no Brasil.

O projeto viabilizou o estabelecimento de mais um canal reverso de devolução de resíduos, além do já existente na loja física do O Boticário/ Barra do Corda-MA, e investir nesses pontos físicos, além da difusão de um conjunto organizado de informações pertinentes a proposta, é de fundamental importância para que o consumidor participe ativamente do processo, como afirmaram Silva et al. (2011) ao fazerem um estudo de caso sobre a franquia do Boticário instalada na cidade de Serra Talhada (PE).

Levar tal vivência para dentro das dinâmicas educacionais de um Instituto Federal de Ensino Tecnológico uniu aspectos da pesquisa científica, extensão, coleta seletiva de resíduos e a busca por uma destinação adequada para esses resíduos, todos diretamente ligados ao rol de ações do que propõem a Educação Ambiental que é identificada, segundo os Referenciais Curriculares Nacionais da Educação Profissional de nível técnico, como um instrumento de revisão dos conceitos sobre o mundo e a vida em sociedade, conduzindo os seres humanos à construção de novos valores sociais, na aquisição de conhecimentos, atitudes, competências e habilidades para a conquista e a manutenção do direito ao meio ambiente equilibrado (BRASIL, 2000).

O lixo produzido pelas dinâmicas de uma comunidade descreve como essa se estabelece em suas relações homem/ homem e homem/ ambiente (CORTEZ et al., 2009), nesse raciocínio e comparando com os dados da figura 2, percebe-se que a cadeia produtiva e de consumo de cosméticos e perfumaria dos partícipes desse projeto esteve baseada, em sua grande maioria, no consumo de produtos com embalagens de vidro, sendo este o material que mais demora para se decompor totalmente na natureza.

Segundo a Associação Nacional de Vidraçarias, ANAVIDRO (2013), a decomposição total do vidro na natureza, dependendo de compostos associados e das condições às quais o material seja exposto, pode durar até 1 milhão de anos e mesmo considerando condições extremas, o tempo mínimo previsto para uma reabsorção desse material pela natureza demoraria uma média de 4 mil anos, o que alerta para um descompasso entre o tempo necessário para a produção, consumo, descarte e recuperação desse material no cotidiano das sociedades quando comparado com as médias obtidas para materiais ecologicamente mais viáveis como o alumínio ou o plástico. 


\section{CONCLUSÕES}

Ao contrário do que se imagina, desmaterializar a sociedade não implica radicalmente excluí-la do consumo de bem materiais, mas sim a adoção de mudanças nas atitudes e nos valores humanos deterministas das demandas para o consumo de bens e serviços, apoiado por um Consumo Verde, consciente, focado em produtos originados por empresas e processos que seguem a ética ambiental e não apenas o eco marketing (CORTEZ et al., 2009).

O trabalho apresentado mostrou que a Logística Reversa é possível operar, mesmo em sistemas menores como num ambiente escolar, como uma ferramenta para fortalecer a consciência ambiental da comunidade e tentar reparar relações desiguais entre o capitalismo e meio ambiente.

A busca por novos padrões produtivos é uma necessidade emergencial dentre as demandas planetárias, demandando um novo perfil de relacionamento entre as formas de emprego e renda e suas influências sobre o meio natural. Sobre isso é possível concluir que a efetividade dessa proposta requer uma força tarefa de todos os envolvidos, das empresas (a exemplo da Logística Reversa praticada pelo grupo Boticário, parceiro desse trabalho), das forças de trabalho intermediárias (como a Associação de Catadores de Materiais Recicláveis, atendida nessa ação) e, principalmente, da sociedade, conscientizada de seu papel ecológico no meio e da importância de suas práticas de consumo consciente e descarte adequado dos resíduos que gera.

O projeto também mostrou que para a Logística Reversa funcionar as empresas que iniciam a cadeia produtiva precisam manter um trabalho colaborativo harmonioso entre a comunidade consumidora e as cooperativas para que se alcance um trabalho de sucesso, além de que um elemento essencial nesse discurso é a disponibilidade de participação ativa e voluntária da própria comunidade, assegurando o engajamento e feedback por meio da reeducação ambiental.

Assim como afirmaram Silva et al. (2011), ficou claro que a participação efetiva da comunidade em ações ambientais como a logística reversa requer um esforço articulado entre a conscientização e operacionalização dos canais reversos da produção.

Foi possível evidenciar também que, dentro de vários limites ajustáveis, o trabalho executado nos moldes da economia solidária é importante por conciliar interesses ambientais, sociais e econômicos potencializando uma vida saudável frente a tríade produção/consumo/pós-consumo.

Por fim, o projeto contribuiu para debates sobre o tema, para fortalecimento da eco consciência dos participantes, para a promoção do engajamento da comunidade escolar em dinâmicas de educação ambiental, focando na importância da reciclagem e reutilização de materiais, permitindo que os alunos participassem da separação de resíduos e do gerenciamento desses para uma futura reutilização dos mesmos, concluindo-se que devido sua importância geral o referido projeto deve ser retomado tão logo as condições sanitárias permitam, a fim de abranger mais alunos para assim ocorrer inclusão de novas turmas, novos parceiros e novas comunidades a serem atendidas. 


\section{REFERÊNCIAS}

ANAVIDRO. Associação Nacional de Vidraçarias. Quanto tempo o vidro leva para se decompor?. São Paulo: ANAVIDRO, 2013.

ANCAT. Associação Nacional dos Catadores e Catadoras de Materiais Recicláveis. Anuário da Reciclagem 2017-2018. São Paulo: LCA Consultores e PRAGMA Soluções Sustentáveis, 2018.

BEZERRA, A. S.. Canal de distribuição reverso: fatores de influência sobre as quantidades de baterias e aparelhos celulares reciclados na cidade de Campina Grande/PB. Dissertação (Mestrado em Desenvolvimento e Meio Ambiente) - Universidade Estadual da Paraíba, Curitiba, 2009.

BRASIL. Ministério da Educação. Educação Profissional: Referenciais Curriculares Nacionais da Educação Profissional de nível técnico. Área profissional: Meio Ambiente. Brasília: MEC, 2000.

BRASIL. Lei n. 12.305 de 02 de agosto de 2010. Institui a Política Nacional de Resíduos Sólidos; altera a lei n. 9.605, de 12 de fevereiro de 1998; e dá outras providências. Brasília: DOU, 2010.

CHEMIN, B. F.. Manual da Univates para trabalhos acadêmicos: planejamento, elaboração e apresentação. 3 ed. Lajeado: UNIVATES, 2015.

COELHO, D. B.; GODOY, A. S.. De catadores de rua a recicladores cooperados: um estudo de caso sobre empreendimentos solidários. Revista de Administração Pública, Rio de Janeiro, v.45, n.3, p.721-749, 2011. DOI: http://doi.org/10.1590/S0034-76122011000300008

CORTEZ, A. T. C.; ORTIGOZA, S. A. G.. Da produção ao consumo: impactos socioambientais no espaço urbano. São Paulo: UNESP, 2009.
DEMAJOROVIC, J.; CAIRES, E. F.; GONÇALVES, L. N. S.; SILVA, M. J. C.. Integrando empresas e cooperativas de catadores em fluxos reversos de resíduos sólidos pós-consumo: o caso Vira-Lata. Cadernos EBAPE.BR/ FGV, Rio de Janeiro, v.12, n.7, p.530-532, 2014. DOI: http://dx.doi.org/10.1590/1679$\underline{39519020}$

GOMES, F. P.; KLEIN, M. J.; STEFFEN, M.; MIRIANI, S.. Introdução à economia solidária. Projeto Casa Brasil, Secretaria Nacional de Economia Solidária. Brasília: Ministério do Trabalho e Emprego, 2007.

GAIGER, L. I.. Empreendimentos econômicos solidários. In: CATTANI, A. D.. A outra economia. Porto Alegre: Veraz Editores, 2003.

LEITE, P. R.; BRITO, E. P. Z.. Reverse logistics of returned products: is Brasil ready for the increasing challenge. In: BUSINESS ASSOCIATION OF LATIN AMERCIAN STUDIES. Anais. São Paulo: 2003.

LOUREIRO, C. F. B.. Educação ambiental: repensando o espaço da cidadania. 5 ed. São Paulo: Cortez, 2011.

NANI, E. L.. Meio ambiente e reciclagem. Curitiba: Juruá, 2012.

RICCHINI, R.. Valor das aparas de papel para reciclagem. São Paulo, 2015.

SILVA, G. F. R.; CARVALHO, P. H. B.; SANTOS, A. N.; FARIAS, A. P. S.. Logística reversa: um estudo de caso numa franquia do Boticário localizada em Serra Talhada (PE). Gestão da Produção, Operações e Sistemas (GEPROS), São Paulo, v.6, n.4, p.169-179, 2011. DOI: http://doi.org/10.15675/gepros.v0i4.903

STURZENEGGER, G.. Você sabe a quantidade de lixo que produz diariamente?. Washington: Banco Interamericano de Desenvolvimento, 2014.

A CBPC - Companhia Brasileira de Produção Científica (CNPJ: 11.221.422/0001-03) detém os direitos materiais desta publicação. Os direitos referem-se à publicação do trabalho em qualquer parte do mundo, incluindo os direitos às renovações, expansões e disseminações da contribuição, bem como outros direitos subsidiários. Todos os trabalhos publicados eletronicamente poderão posteriormente ser publicados em coletâneas impressas sob coordenação da Sustenere Publishing, da Companhia Brasileira de Produção Científica e seus parceiros autorizados. Os (as) autores (as) preservam os direitos autorais, mas não têm permissão para a publicação da contribuição em outro meio, impresso ou digital, em português ou em tradução. 